\title{
The permeation action of gases coolant and lubricant in cutting zone
}

\author{
Y. Zhang ${ }^{1, a,{ }^{*}, \text { L.Han }^{1} \text {, Q.Li }}{ }^{1}$,L.P.Dong ${ }^{1}$, Y.Q.Ma ${ }^{2}$ \\ ${ }^{1}$ School of Mechanical Engineering, Shenyang University of Technology, China \\ ${ }^{2}$ Shenyang YIXIN Science and Technology Development Company Ltd.,, China \\ azhy@sut.edu.cn, sutzhy@qq.com
}

Keywords: metal cutting; cutting zone; conical capillary model; kinetics diameter;

Abstract. The gases of nitrogen, oxygen, argon and carbon dioxide were employed as coolant and lubricant in metal cutting. Therefore, the smaller kinetic diameter of gas, leads to the lower cutting forces and deformation coefficient. A conical capillary model is proposed, based on the experimental results and the theory analysis of stress distributions at the tool-chip interface, and the kinetics differential equation of gas flow is solute. The velocity and flux of gas molecule is presented. In the capillary, the adsorption of tool-chip interface results in boundary lubricating film; the conical shape of capillary limits the depth of coolant and lubricant penetrating; and the negative press is the motivity for coolant and lubricant penetrating. The study results show the molecule size of the coolant and lubricant could effect on its performances, and the coolant and lubricant with a relatively small molecule may have the particularly effective nature, in metal cutting.

\section{Introduction}

In metal cutting, coolant and lubrication is usually applied to reduce the cutting force and the cutting temperature. To their action process and mechanism, it has been only given some qualitative analyses at many situations until now. Generally, capillarity is used to explain the penetrating process of coolant and lubrication. There are lots of microcosmic apertures at the cutting zone and coolant and lubrication can penetrate these apertures, and then form boundary layer rapidly during metal cutting. Correspondingly, these microcosmic apertures are described as capillaries with a given geometry entity. And several researchers have also indicated that lubricating action occurred mainly by penetration of a surrounding material through capillaries existing between the tool and the proceed material. Merchant reported that microcosmic apertures could be observed with microscope, and the radius of capillary was about $2 \times 10^{-7} \mathrm{~m}$ [1]. Williams proposed that the capillary could be assumed as a cuboid with the dimensions of $l \times m a \times a$, and molecular size and vapor pressure played an important part in molecular transport in the tool-chip interface [2,3]. Godlevski presented a cylindrical capillarity model with the size of $l \times r$, and analyzed the process of cutting lubricant filling capillarity [4,5]. The authors, based on Godlevski's capillarity model, examined the different process of coolant and lubricant accessing capillary as vapor phase and liquid phase [6]. However, more experimental and theoretical studies need to be devoted to discussing the lubricating process and mechanism on the viewpoint of capillary theory.

In this paper, a new capillary model is proposed, based on the experimental results. This model, to some extent, can explain that lubricating action is effected by the molecule size of coolant and lubrication.

\section{Experimental study}

Experiments were carried out on a general lathe CA6140, powered by a $7.5 \mathrm{kw}$ electric motor giving a speed range of 10 1400 rev/min and a feed range of $0.014 \sim 3.16 \mathrm{~mm} / \mathrm{rev}$. The materials used were medium carbon steel 45 (C 0.44\%, Si 0.21\%, Mn 0.62\%, P 0.02\%, S 0.025\%, Cr 0.01\%, Cu $0.01 \%$, and $\sigma_{\mathrm{b}} 590 \mathrm{MPa}, \delta 7.5 \%$,) with the size of $\varphi 125 \mathrm{~mm} \times 650 \mathrm{~mm}$. The cutting tools were YT15 
(P10 grade) uncoated inserts. A number of angles for tool geometry were $\gamma_{0}=14^{\circ}, \alpha_{o}=\alpha_{o}^{\prime}=6^{o}$, $\kappa_{\mathrm{r}}=75^{\circ}, \kappa_{o}^{\prime}=15^{\circ}, \lambda_{\mathrm{s}}=-6^{\circ}$.

The used cutting speed was $100 \mathrm{~m} / \mathrm{min}$ and kept constant for all experiments. The applied depths of cutting were $1,1.5,2,2.5$ and $3 \mathrm{~mm}$ with the feed at $0.15 \mathrm{~mm} / \mathrm{rev}$, then the feeds were selected 0.1 , $0.15,0.2$ and $0.3 \mathrm{~mm} / \mathrm{rev}$ with the depth of cutting at $2 \mathrm{~mm}$.

The gases of nitrogen, oxygen, argon and carbon dioxide were employed as coolant and lubricant in cutting. The gas tubes were standard types with suitable pressure regulators for each gas. The plastic pipe with an outer diameter of $12 \mathrm{~mm}$ and inner diameter of $10 \mathrm{~mm}$ with $3 \mathrm{~m}$ length was used to connect regulators and nozzle. $2 \mathrm{~mm}$

The nozzle and the cooling distance were the same as those of water vapor used in cutting. These gases temperatures were $20 \pm 2^{\circ} \mathrm{C}$ and the pressures and the fluxes in the pipe were $0.2 \mathrm{MPa}$ and $45 \mathrm{~L} / \mathrm{min}$.

Under the dry cutting and gases applications conditions, the main cutting force was measured by Vertical Parallel Octagon resistance strain turning dynamometer, and the chip thicknesses were obtained by using tool microscope $\mathrm{n}$ and then deformation coefficients could be calculated.

\section{Experimental results}

The cutting forces were obtained separately for dry machining and forth kinds of gases applications and presented in Fig.1.

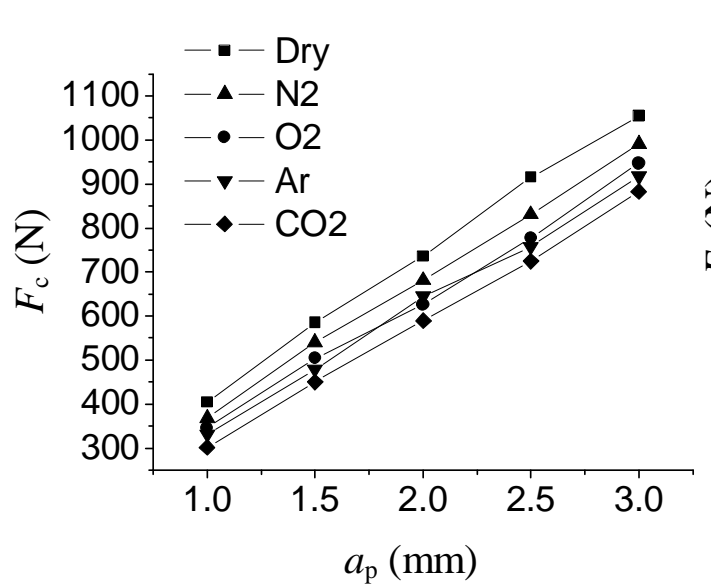

(a) $F_{\mathrm{c}}-a_{\mathrm{p}}$

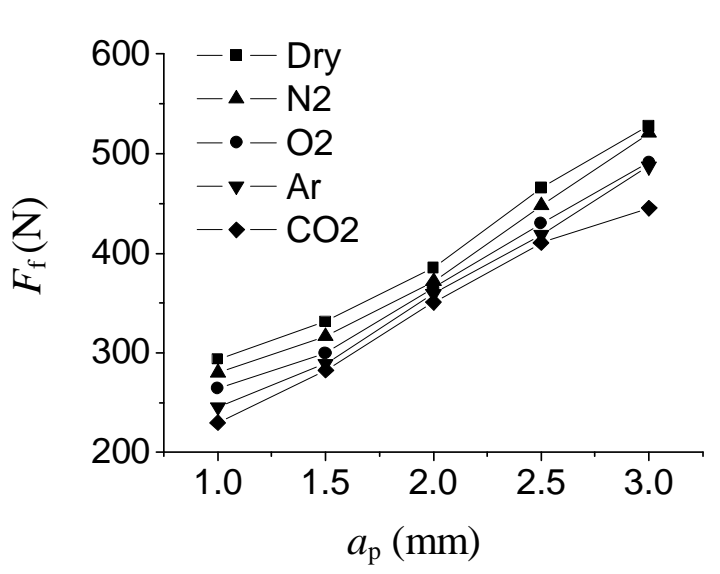

(c) $F_{\mathrm{f}}-a_{\mathrm{p}}$

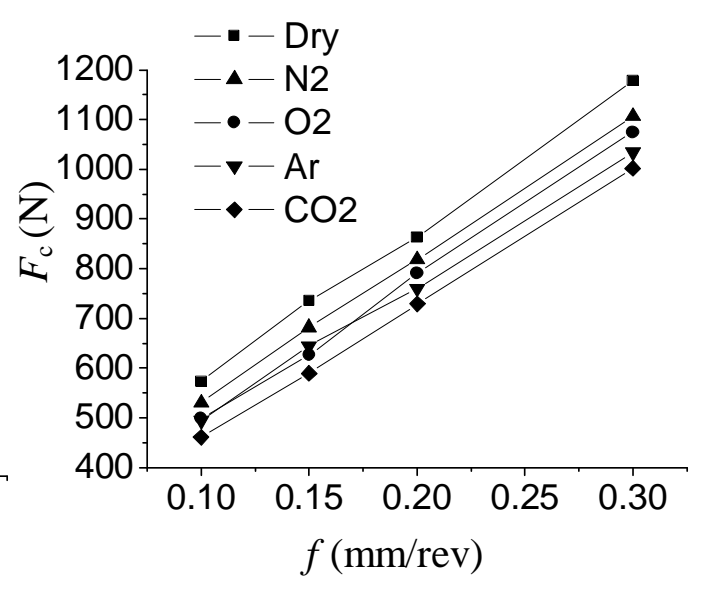

(b) $F_{\mathrm{c}}-f$

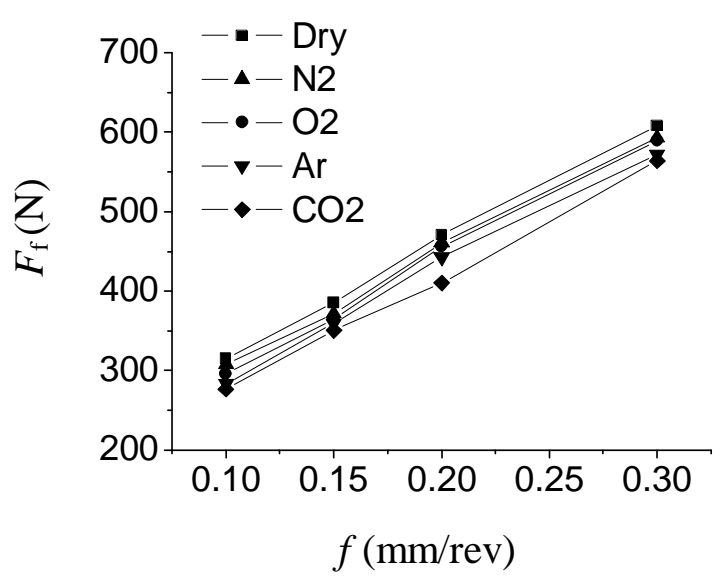

(d) $F_{\mathrm{f}}-f$

Fig. 1 Cutting forces

Dry cutting gave the highest cutting forces, which indicated that all the gases functioned as coolant and lubrication in metal cutting. Among the gas applications, nitrogen produced the highest 
cutting forces. Oxygen used gave higher ones than did argon used. And carbon dioxide produced the lowest ones. The low cutting forces indicate that coolant and lubricant can reach the tool-chip interface, form the lubricating film and reduce the friction between the tool and chip.

In O.Çakır's study [7], nitrogen, oxygen and carbon dioxide were applied, and the similar results were obtained.

In the above-mentioned experimental results and theory analysis, it can be assumed that each capillary meets the normal and shear stress distribution in the sliding zone, and has a conical form with dimensions $r$ and $l$ (see fig.2).

\section{Kinetics study}

In the conical capillary, the coolant and lubricant flow can be presented in the fig. 3 , where $x, \phi, z$ denote the radial, azimuthal, and axial coordinates and $u_{x}, u_{\phi}, u_{z}$ denote the velocity components in the respective directions.

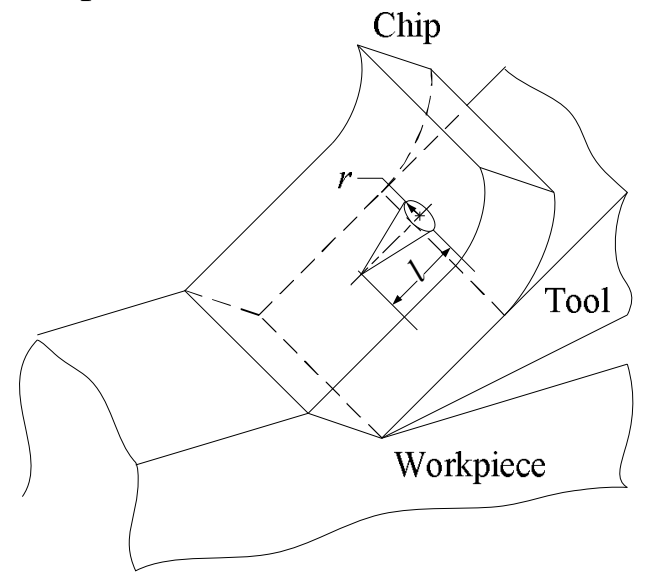

Fig.2 the conical capillary model

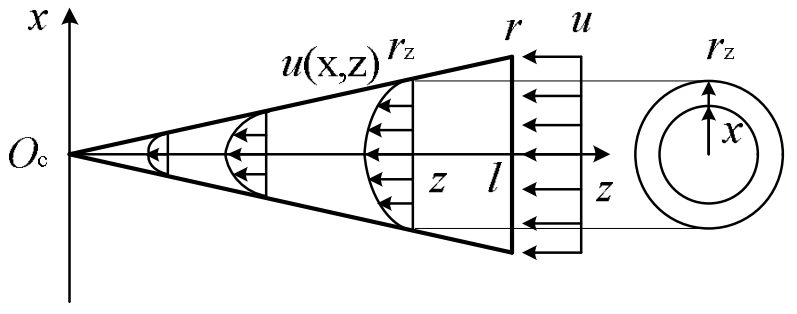

Fig. 3 the coolant and lubricant flow in the conical capillary

In the cylindrical coordinate system, for incompressible flow the Navier-Stokes equation is as follow[11]:

$$
\rho\left(\frac{\partial u_{z}}{\partial t}+u_{x} \frac{\partial u_{z}}{\partial x}+\frac{u_{\phi}}{x} \frac{\partial u_{z}}{\partial \phi}+u_{z} \frac{\partial u_{z}}{\partial z}\right)=F_{z}-\frac{\partial p}{\partial z}+\mu\left(\frac{\partial^{2} u_{z}}{\partial x^{2}}+\frac{1}{x} \frac{\partial u_{z}}{\partial x}+\frac{1}{x^{2}} \frac{\partial^{2} u_{z}}{\partial \phi^{2}}+\frac{\partial^{2} u_{z}}{\partial z^{2}}\right)
$$

Where $\rho$ is density; $t$ is time; $F_{z}$ is body force component in the $z$ direction; $p$ is pressure; $\mu$ is the viscosity.

The boundary conditions are $x=r_{\mathrm{z}}: u=0$ and $x=0: u=u_{\mathrm{m}}$.

It is assumed that the coolant and lubricant motion is a parallel flow in the conical capillary, then $\frac{\partial u_{z}}{\partial t}=0, \frac{\partial u_{z}}{\partial x}=0, \frac{\partial u_{z}}{\partial \phi}=0, \frac{\partial u_{z}}{\partial z}=0, F_{z}=0, \frac{\partial^{2} u_{z}}{\partial \phi^{2}}=0, \frac{\partial^{2} u_{z}}{\partial z^{2}}=0$, and equation (1) becomes

$$
\frac{d p}{d z}=\mu\left(\frac{d^{2} u_{z}}{d x^{2}}+\frac{1}{x} \frac{d u_{z}}{d x}\right)
$$

The flow of coolant and lubricant is affected by the boundary layer action, due to the adsorption of the tool-chip interface, and the viscosity will be

$$
\mu=\mu_{0}+\Delta \mu=\mu_{0}+\frac{\phi}{\left(\frac{r}{l} z-x\right)^{n}}=\mu_{0}+\frac{\phi l^{n}}{(r z-l x)^{n}} \approx \frac{\phi l^{n}}{(r z-l x)^{n}}
$$

Where $\mu_{0}$ is general viscosity, and can be neglected in the capillary, $\Delta \mu$ is the viscosity increment from the adsorption of tool-chip interface.

According to derivation, we can obtain 


$$
Q=-\frac{1}{\phi} \frac{\pi}{(n+1)(n+2)}\left[\frac{1}{(n+2)(n+3)}+\frac{2(n+1)}{(n+2)(n+3)(n+4)}\right]\left(\frac{r z}{l}\right)^{n+4} \times \frac{d p}{d z}
$$

When $z=l$ in equation (10) and (12), we get $u=0, Q=0$. It indicates that at the end of capillary, all the gas molecules are adsorbed. And the minus of equation (4) suggests that the direction of pressure rising is opposite with that of gas molecule moving in the capillary.

\section{Conclusions}

(1) As the gases of nitrogen, oxygen, argon and carbon dioxide applied in metal cutting experiments, the smaller kinetic diameter of gas, the lower main cutting force and deformation coefficient can be obtained.

(2) Combined the stress distribution on the tool-chip interface, a conical capillary model is proposed based on the prevenient research and experimental results.

(3) According to theory analysis results, after gas lubricant come into in the conical capillary, the velocity and flux all decrease from the open end to the close end, due to the action of adsorption and the effect of boundary layer.

\section{Acknowledgements}

This research reported in the paper is financially supported by Foundation of Liaoning Province

Education Department (L2012042), Doctoral Research Foundations of Liaoning Province(20121058). These supports are greatly acknowledged.

\section{References}

[1] Merchant M E. The physical chemistry of cutting fluid action. ACS Division of Petroleum Chemistry. 4A(1958)179-189

[2] J.A. Williams, D. Tabor, The role of lubricants in machining, Wear, 43 (1977) 275-292

[3] J.A. Williams, The action of lubricants in metal cutting, Journal of Mechanical Engineering Science, 19 (1977)202-212

[4] V. A.Godlevski, A.V. Volkov. The Kinetics of Lubricant Penetration Action during machining. Lubrication Science. 9(1997)127-140

[5] V.A.Godlevski , A.V. Volkov. A Description of the Lubricating Action of the Tribo-Active Components of cutting Fluids. Lubrication Science. 11(1998)51-62

[6] Junyan Liu, Rongdi Han, Yongfeng Sun, Research on experiments and action mechanism with water vapor as coolant and lubricant in Green cutting, International Journal of Machine Tools \& Manufacture, 45(2005) 687-694

[7] O.Çakır, M.Kıyak, E.Altan. Comparison of gases applications to wet and dry cuttings in turning. Journal of Materials Processing Technology, 153-154 (2004) 35 41

[8] M.C.Shaw, Metal Cutting Principles. Oxford: Claredon Press, 1984: 292-332

[9] E.M Trent, Metal cutting ( $3^{\text {rd }}$ Ed.). Oxford: Butterworth Heinemann, 1991

[10] G.M.L. Gladwell. Contact Problems in the Classical Theory of Elasticity. Maryland: Sijthoff \& Noordhoff, 1980

[11] Hermann Schlichting. Boundary-layer Theory (Seventh Edition). New York: McGraw-Hill Book Company, 1979 